SHORT COMMUNICATION

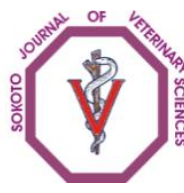

Sokoto Journal of Veterinary Sciences

(P-ISSN 1595-093X/ E-ISSN 2315-6201)

Tenuche \& Emikpe /Sokoto Journal of Veterinary Sciences (2015) 13(1): 48-52

http://dx.doi.org/10.4314/sokjvs.v13i1.7

\title{
Effect of intranasal recombinant Mannheimia haemolytica vaccination on some haematological indices of goats infected with peste des petits ruminants virus
}

\author{
OZ Tenuche ${ }^{1}$ \& BO Emikpe E $^{2 *}$ \\ 1. Department of Veterinary Pathology, University of Abuja, Abuja, Nigeria \\ 2. School of Veterinary Medicine, Kwame Nkrumah University of Science and Technology, \\ Kumasi, Ghana
}

*Correspondence: Tel.: +2348066486080, E-mail: banabis2001@yahoo.com

\begin{abstract}
There is dearth of information on the haematological changes associated with Mannheimia haemolytica vaccination in goats, hence this report which describes some haematological changes observed following vaccination with intranasal Recombinant Mannheimia haemolytica vaccine in goats naturally infected with peste des petits ruminants (PPR) virus. Twenty one (male, $n=11$; and female, $n=10$ ) goats were assigned to three vaccinated groups (A, B and D) with five goats per group (male: 3, female: 2 ), while the control group had 6 goats. Group A was vaccinated once intranasally, group B was vaccinated intranasally twice at one week interval and group D was vaccinated intranasally twice at two weeks interval. The control group (C) was not vaccinated. The vaccinated and control groups were challenged by comingling with pneumonic goats to simulate the field experience. PPR virus infection was later diagnosed in all the groups post vaccination. An average of four animals per treatment group in post-vaccination days were bled once weekly for six weeks (every week) to evaluate some haematological changes. The PCV values were within the normal range, while there was a decline in lymphocyte count at week 5, and a steady increase in neutrophil count in group A. In Group B, there was similar decline in lymphocyte count from the sixth week, while in groups $C$ (Control) and $D$, the lymphocyte count declined at the $7^{\text {th }}$ week, as the neutrophil counts increased. There were no significant changes in monocyte and eosinophil counts. The degree of changes in lymphocyte and neutrophil counts was mild in group B and marked in group D. This study revealed that intranasal vaccination of recombinant Mannheimia haemolytica vaccine in the presence of PPR virus outbreak results in mild hematological derangement when the goats were vaccinated with Mannheimia haemolytica bacterin at a week interval.
\end{abstract}

Keywords: Goats, Haematology, Intranasal Recombinant Mannheimia haemolytica, Peste des Petits Ruminants, Vaccination

Received: 14-09-2014

Accepted: 20-03-2015

\section{Introduction}

African small ruminant population was estimated to be 171 million with about 34.5 million found in Nigeria. Goats are more commonly owned by farming units in Africa than other ruminants (FAO, 1991). They are a major source of meat, milk, and skin (Williamson \& Payne, 1978). Goats continue to play an important role in the welfare of smallholder arable farmers as they improve the livelihoods of women and children often entrusted within their (Ikwuegbu et al., 1995).

Diseases still remain the most important impediment to goat production in the tropics. Pneumonia is still one the diseases that poses a major constraint to small ruminant production in 
Nigeria (Emikpe et al., 2013a, Emikpe et al., 2013b). common causes of bacterial pneumonia in goats in sub-Saharan Africa, parts of Asia and Arabian Penisular (Emikpe et al., 2010). Mannheimiosis is a well-known bacterial pneumonic disease of domestic and wild small ruminants and is characterized by pyrexia, mucopurulent nasal discharges, fibrinous pneumonia and ultimately, death (Emikpe \& Akpavie, 2010). Factors such as stress and overcrowding had been identified as predisposing factors to caprine pneumonia, but investigation of their role in this condition is still not clear (ZamriSaad et al., 1989, Emikpe et al., 2014). Domestic animals especially goats are constantly subjected to some of the most stressful conditions in the humid zone where Mannheimia haemolytica complicated PPRV infection had been reported in goats (Emikpe et al., 2010, Emikpe et al., 2013a). This necessitates the need to produce an indigenous vaccine to curb the bacterial complication often associated with viral pneumonia in Nigerian goats. (Emikpe et al., 2013a). Thus, the control and prevention of most bacterial respiratory diseases had focused on the use of intranasal vaccines which induce strong mucosal responses and protection in small ruminants (ZamriSaad et al., 1989, Tenuche et al., 2013). The use and safety of vaccination against Mannheimiosis, even though common in some countries (Zamri-Saad et al., 1994, Purdy et al., 1997), had not been reported in Nigerian breeds of goats.

Previous reports showed that intranasal vaccination of recombinant Mannheimia haemolytica bacterine is not protective against naturally occurring pneumonia in Nigeria inspite of the ability to induce strong mucosal immunity in the respiratory tracts (Emikpe et al., 2013b, Tenuche et al., 2013), however there is dearth of information on the safety of Mannheimia haemolytica vaccination especially in countries where viral respiratory disease such as PPR is endemic. This report describes some haematological changes observed in intranasal recombinant Mannheimia haemolytica vaccinated goats that had Peste des Petits ruminants Virus infection in the course of evaluation of efficacy of the vaccine in goats.

\section{Materials and Methods}

Animal

The experimental protocol had been previously described (Emikpe et al., 2013b). Briefly, twenty one (male, $n=11$; and female, $n=10$ ) West African Dwarf
Mannheimia haemolytica $(\mathrm{MH})$ is one of the most (WAD) goats obtained from a recognized breeding farm, six months of age, of average weight of $7 \mathrm{~kg}$ were used for the experiment. They were conditioned for 14 days before the intervention and vital signs (rectal temperature, pulse and respiratory rates) were monitored daily to ascertain that they remained afebrile and free of any clinical signs of disease. The animals were then randomly assigned to four well partitioned, fly proof pens of the Veterinary Pathology Department, in the experimental animal unit of the Faculty of Veterinary Medicine, University of Ibadan. The animals were fed daily with cut grass; supplemented feed and clean drinking water was available ad libitum. Each intended vaccinated group ( $A, B$ and $D$ ) had five goats (male: 3 , female: 2 ) while the control group (C) had 6 goats.

The study was reviewed and approved by the ethical board of the Faculty of Veterinary Medicine, University of Ibadan and adequate measures were taken to minimize pain or discomfort.

\section{Vaccine}

The vaccine used was obtained from Malasia. It contained cultures of the recombinant cell (Malaysian patent no. PI 20070305 on "Mannheimia haemolytica bacterial polypeptides and sequences, gene sequences and uses thereof" in the name of Universiti Putra Malaysia) prepared using pET-Blue-2 (Merck) were harvested and killed in $0.5 \%$ formalinPBS overnight (Sabri, 2006).

\section{Experimental procedure}

Group A was vaccinated once intranasally. This was carried out by introducing a single spray of the vaccine directly into each nostril. The same was done for groups B (vaccinated twice at one week interval) and $D$ (vaccinated twice at two weeks interval). Group C served as the control group and was not vaccinated. The experimental goats were not experimentally infected with PPR virus, however the vaccinated and control groups were challenged by comingling with pneumonic goats to simulate the field experience. Peste des Petits ruminants (PPR) virus infection was later diagnosed all the groups post $\mathrm{MH}$ (Mannheimia haemolytica) vaccination by clinical features of pneumonia and histopathological changes consistent with PPR as observed in lungs and intestinal tissues of goats from all the groups (Emikpe \& Akpavie, 2011). 


\section{Haematology}

All or surviving animals in post-vaccination days were bled by jugular venepuncture once every week over a period of 8 weeks. $2 \mathrm{mls}$ of blood were collected on each occasion into containers with ethylenediamine tetra acetate (EDTA) for hematological studies. The packed cell volume (PCV) was determined by the microhaematocrit method while the differential leucocyte counts were determined from Giemsa stained blood smears (Jain, 1986)

\section{Statistical analysis}

Statistical analysis was carried out with ANOVA and Duncan multiple range test of significance $(<0.05)$ for means of the parameters recorded (SPSS-20) (Petrie \& Watson, 1999).

\section{Results}

Table 1: The packed cell volume changes in the different vaccinated groups of goats

\begin{tabular}{ccccc}
\hline & \multicolumn{4}{c}{ Groups (Mean PCV \pm SD) } \\
\cline { 2 - 5 } WEEKS & $\mathrm{A}$ & $\mathrm{B}$ & $\mathrm{C}$ & $\mathrm{D}$ \\
\hline 1 & $25.80 \pm 2.95^{a}$ & $26.00 \pm 3.16^{a}$ & $25.50 \pm 4.95^{a}$ & $28.77 \pm 2.07^{a}$ \\
2 & $26.80 \pm 7.06^{a}$ & $24.60 \pm 2.70^{a}$ & $30.33 \pm 0.58^{a}$ & $29.60 \pm 6.80^{a}$ \\
3 & $24.60 \pm 6.77^{a}$ & $28.80 \pm 3.63^{a}$ & $31.00 \pm 1.00^{a}$ & $31.00 \pm 3.60^{a}$ \\
4 & $31.75 \pm 6.02^{a b}$ & $23.60 \pm 5.37^{b}$ & $31.50 \pm 2.12^{a b}$ & $34.60 \pm 3.13^{a}$ \\
5 & $34.00 \pm 0.00^{a}$ & $31.40 \pm 5.68^{a}$ & $32.50 \pm 2.12^{a}$ & $24.50 \pm 4.44^{a}$ \\
6 & $32.00 \pm 0.00^{a}$ & $21.80 \pm 6.06^{b}$ & $27.00 \pm 0.00^{a b}$ & $26.33 \pm 3.06^{a b}$ \\
7 & $29.00 \pm 0.00^{a}$ & $24.67 \pm 6.03^{a}$ & $26.50 \pm 4.95^{a}$ & $22.50 \pm 2.12^{a}$ \\
8 & $27.00 \pm 0.00^{a b}$ & $26.00 \pm 9.90^{a b}$ & $35.00 \pm 0.00^{a}$ & $20.50 \pm 0.71^{b}$ \\
Total & $28.04 \pm 5.48^{a b}$ & $25.91 \pm 5.43^{b}$ & $29.80 \pm 3.86^{a}$ & $27.81 \pm 6.19^{a b}$ \\
\hline
\end{tabular}

Note: Mean $\pm S D$ across a row with different superscripts are significantly different with $a>b(<0.05)$

Table 2: The average lymphocyte changes in the different vaccinated groups of goats

\begin{tabular}{ccccc}
\hline & \multicolumn{4}{c}{ Treatments (Mean \pm SD) } \\
\cline { 2 - 5 } WEEKS & $\mathrm{A}$ & $\mathrm{B}$ & $\mathrm{C}$ & $\mathrm{D}$ \\
\hline 1 & $43.20 \pm 16.16^{a}$ & $61.80 \pm 18.19^{a}$ & $50.00 \pm 22.63^{a}$ & $57.6 \pm 3.36^{a}$ \\
2 & $47.00 \pm 14.32^{a}$ & $62.20 \pm 9.39^{a}$ & $60.67 \pm 11.02^{a}$ & $65.20 \pm 13.63^{a}$ \\
3 & $47.20 \pm 18.19^{a}$ & $53.20 \pm 14.04^{a}$ & $60.00 \pm 5.00^{a}$ & $61.40 \pm 16.90^{a}$ \\
4 & $43.25 \pm 7.93^{a}$ & $31.00 \pm 15.26^{a}$ & $56.00 \pm 11.31^{a}$ & $55.80 \pm 23.89^{a}$ \\
5 & $49.00 \pm 0.00^{b}$ & $53.20 \pm 17.70^{b}$ & $86.50 \pm 3.54^{a}$ & $72.25 \pm 8.88^{a b}$ \\
6 & $36.00 \pm 0.00^{a}$ & $41.40 \pm 32.61^{a}$ & $69.00 \pm 18.39^{a}$ & $47.67 \pm 29.74^{a}$ \\
7 & $35.00 \pm 0.00^{a}$ & $41.00 \pm 18.08^{a}$ & $39.50 \pm 2.12^{a}$ & $45.00 \pm 28.28^{a}$ \\
8 & $35.00 \pm 0.00^{a}$ & $48.00 \pm 19.80^{a}$ & $38.00 \pm 0.00^{a}$ & $46.00 \pm 35.36^{a}$ \\
Total & $43.33 \pm 12.35^{b}$ & $49.51 \pm 20.23^{a b}$ & $57.33 \pm 18.40^{a}$ & $58.05 \pm 21.36^{a}$ \\
\hline
\end{tabular}

Note: Mean $\pm S D$ across a row with different superscripts are significantly different with $a>b .(<0.05)$ Mean separation done with Duncan Multiple Range test 
Table 3: The average neutrophil changes in the different vaccinated groups of goats

\begin{tabular}{ccccc}
\hline & \multicolumn{4}{c}{ NEUTROPHIL } \\
\hline WEEKS & $\mathrm{A}$ & Treatments (Mean \pm SD) \\
\cline { 2 - 5 } 1 & $51.80 \pm 15.64^{\mathrm{a}}$ & $32.20 \pm 15.94^{\mathrm{a}}$ & $\mathrm{C}$ & $\mathrm{D}$ \\
\hline 2 & $49.80 \pm 12.76^{\mathrm{a}}$ & $35.60 \pm 9.71^{\mathrm{a}}$ & $32.00 \pm 7.00^{\mathrm{a}}$ & $32.20 \pm 13.72^{\mathrm{a}}$ \\
3 & $50.80 \pm 18.05^{\mathrm{a}}$ & $44.40 \pm 12.95^{\mathrm{a}}$ & $33.33 \pm 6.65^{\mathrm{a}}$ & $37.00 \pm 11.02^{\mathrm{a}}$ \\
4 & $54.50 \pm 7.77^{a}$ & $66.20 \pm 15.06^{a}$ & $42.00 \pm 12.73^{a}$ & $43.00 \pm 24.81^{a}$ \\
5 & $49.00 \pm 0.00^{a}$ & $43.20 \pm 17.51^{a}$ & $14.50 \pm 6.36^{b}$ & $23.00 \pm 9.45^{a b}$ \\
6 & $62.00 \pm 0.00^{a}$ & $56.80 \pm 33.03^{a}$ & $30.00 \pm 21.21^{a}$ & $51.00 \pm 31.18^{a}$ \\
7 & $62.00 \pm 0.00^{\mathrm{a}}$ & $54.00 \pm 23.58^{\mathrm{a}}$ & $44.00 \pm 9.90^{\mathrm{a}}$ & $45.50 \pm 37.48^{\mathrm{a}}$ \\
8 & $63.00 \pm 0.00^{\mathrm{a}}$ & $50.00 \pm 21.21^{\mathrm{a}}$ & $56.00 \pm 0.00^{\mathrm{a}}$ & $50.50 \pm 34.65^{\mathrm{a}}$ \\
Total & $53.78 \pm 12.00^{a}$ & $47.26 \pm 20.63^{a b}$ & $37.47 \pm 16.09^{b}$ & $38.71 \pm 22.52^{b}$ \\
\hline
\end{tabular}

Note: Mean $\pm S D$ across a row with different superscripts are significantly different with $a>b$. $(<0.05)$

Mean separation done with Duncan Multiple Range test

\section{Discussion}

This report appears to be the first report describing some haematological changes observed in intranasal Recombinant Mannheimia haemolytica vaccinated goats that had Peste des Petits ruminants Virus infection. In this study, the differential cell count was used to ascertain the presence or absence of inflammatory response in the leukogram of all the groups. The reduced lymphocytes below normal values in group $A$ at two weeks and the increasing neutrophil counts suggests a possible acute bacterial infection. In group $B$, there was an increase in lymphocyte count and a decline in the neutrophil while groups $\mathrm{C}$ and $\mathrm{D}$ maintained a similar lymphocyte count value till the sixth week with increased neutrophil count at $7^{\text {th }}$ week. This observation is similar to that of Ganheim et al. (2003) where Mannheimia haemolytica infection was reported to induce an increase in leukocyte count especially neutrophils with low lymphocyte count. The degree of changes in lymphocyte and

\section{References}

Emikpe BO \& Akpavie SO (2010). The clinical and pathological features of experimental Mannheimia hemolytica A2 in West African Dwarf Goats. Bulletin of Animal Production and Health in Africa, 58(3): 261-270.

Emikpe BO \& Akpavie SO (2011). The clinicopathologic effects of Peste des petits ruminants virus in experimentally infected West African dwarf goats. Small ruminant Research. 95(2-3): 168-173.

Emikpe BO, Jarikre TA \& Eyarefe OD (2013a). Disease pattern and type of pneumonia in neutrophil values in all the groups showed that group $B$ had the mildest inflammatory response possibly suggesting adequate immunity while that of group D showed a severe acute inflammatory response.

In conclusion, this study has revealed that intranasal vaccination of recombinant Mannheimia haemolytica bacterine does not cause severe hematological derangement when the goats were vaccinated with Mannheimia haemolytica bacterine at a week interval even in the presence of PPR outbreak, while severe derangement was observed in animals vaccinated at two weeks interval.

\section{Acknowledgement}

The authors are grateful to Dr Sabri M.Yussof of the Department of Pathology and Microbiology, Faculty of Veterinary Pathology, Universiti Putra Malaysia, for donating the vaccine used in this study.

Nigerian small ruminants. African Journal of Biomedical Research 16(3): 107 - 113.

Emikpe BO, Sabri YM, Akpavie SO \& Zamri-Saad M (2010). Experimental infection of Peste des petits ruminants virus and Mannheimia haemolytica A2 in goats: Immunolocalisation of Mannheimia haemolytica antigens. Veterinary Research Communication 34(7): 569-578.

Emikpe BO, Tenuche O \& Sabri MY (2013b). Intranasal administration of inactivated recombinant Mannheimia hemolytica 
vaccine protective against naturally occurring pneumonia in Nigerian goats. African Journal of Biomedical Research 16(3): $185-191$

Emikpe BO, Tijani LA, Karim Mariam O, Omoniyi AS \& Akanbi IM (2014). The isolation and antibiogram of pneumonic pasteurellosis causing microbes from the nasopharynx of transport stressed goats. African Journal of Microbiology Research (8)5: 441-445.

FAO (Food and Agriculture organizations of the United Nations) (1991). Livestock and Livestock Products. Quarterly Bulletin of Statistics. 4(3): 39.

Ganheim C, Hulten C, Carlsson U, Kindahl H, Niskanen R \&Waller KP (2003). The acute phase response in calves experimentally infected with bovine viral diarrhoea virus and/or Mannheimia haemolytica. Journal of Veterinary Medicine B; 50(4):183-190.

Ikwuegbu OA, Tarawali G \& Rege JEO (1995). Effects of fodder banks on growth and survival of West African Dwarf goats under village conditions in sub humid Nigeria. Small Ruminant Research, 17(2):101-109.

Jain NC (1986). Schalm's Veterinary Haematology. Fouth edition (Jain NC, editor), Lea and Febiger, Philadelphia. Pp 1221.

Petrie A \& Watson P (1999). Statistics for Veterinary and Animal Science. Blackwell Science, Oxford. Pp 57-60.

Purdy CW, Raleigh RH, Collins JK, Watts JL \& Straus DC (1997). Serotyping and enzyme characterization of Pasteurella hemolytica and Pasteurella multocida isolates recovered from pneumonic lungs of stressed feeder calves. Current Microbiology, 34(4):244-249.

Tenuche O, Emikpe BO \& Sabri MY (2013). Cellular and mucosal responses in the respiratory tract of Nigerian goats following intranasal administration of inactivated recombinant Mannheimia hemolytica bacterine. Nigerian Journal of Physiological Science 28(2):121123.

Sabri MY (2006). Isolation, purification, cloning and sequencing of the $30 \mathrm{kDa}$ outer membrane protein of Pasteurella haemolytica A7 for subunit vaccine, PhD Thesis, Department of Pathology and Microbiology, Faculty of Veterinary Medicine, Universiti Putra Malaysia, Malaysia. Pp 1-210.

Williamson G \& Payne WJA (1978). An introduction to animal husbandry in the tropics. Longman, London, UK. Pp 463-483.

Zamri-Saad M, Sharif H \& Basri K. (1989). Microbiological and pathological evaluation of vaccination against naturally occurring caprine pasteurellosis. Veterinary Records 124(7):171-172.

Zamri-Saad M, Subramaniam $P$, Sheikh Omar AR, Sani RA \& Rasedee A (1994). The role of concurrent haemonchosis in the development of pneumonic pasteurellosis in goats. Veterinary Research Communications 18(2): 119-122. 